\title{
Photochemically Activated Thiol-Michael Reactions via a Photolatent N-Heterocyclic Carbene
}

\author{
Abraham Chemtob, ${ }^{*},+$ Bao Tram Vu Ngoc, ${ }^{\dagger, *}$ Julien Pinaud, ${ }^{\S}$ Patrick Lacroix-Desmazes, ${ }^{\S}$ \\ Valérie Héroguez, \\ †' Institut de Science des Matériaux de Mulhouse, IS2M UMR 7361 CNRS, Université de \\ Haute-Alsace, France \\ $\neq$ Université de Strasbourg, France \\ $\S$ Institut Charles Gerhardt Montpellier, ICGM UMR 5253 Université de Montpellier, CNRS, \\ ENSCM, Montpellier, France \\ $\varsigma$ Université de Bordeaux, CNRS, Bordeaux INP, LCPO, UMR 5629, F-33600, Pessac, \\ France.
}

\begin{abstract}
While N-heterocyclic carbenes (NHCs) have proven highly effective in various polymerization reactions, the drawback is their high sensitivity towards air and water, which necessitates handling under rigorously anhydrous conditions. In this report, an air-stable two-component NHC photogenerator - 2-isopropylthioxanthone (ITX) as photosensitive species and 1,3bis(mesityl)imidazolium tetraphenylborate $\left(\mathrm{IMesH}^{+} \mathrm{BPh}_{4}^{-}\right)$acting as $\mathrm{NHC}$ protected precursor - has been utilized to organocatalyze thiol-Michael reaction for small molecule and polymer synthesis. The feasibility of photoNHC catalysis in addition reactions involving thiol and ene molecules was investigated using ${ }^{1} \mathrm{H}$ NMR spectroscopy. The synthesis of cross-linked polythioether polymer via a step-growth polymerization was then studied using FTIR spectroscopy, optical pyrometry and gel content measurements.
\end{abstract}




\section{INTRODUCTION}

Organo-mediated polymerizations are characterized by the use of small organic molecules acting as highly active initiators or catalysts. Many classes of organic activators have been well known for some years, most of which being Brønsted/Lewis acids or bases. ${ }^{[1]}$ The most prominent examples are sulfonic acids for initiating anionic chain polymerization or cyclic guanidine for catalyzing polyurethane step polymerization. ${ }^{[2-3]} \mathrm{A}$ renewed interest is emerging in this field with the primary objective of replacing conventional metal or organometallic compounds to reduce cost, toxicity, and sensitivity towards air or oxygen. In a few cases, organic activators can even drive higher polymerization rates through activation of monomer or polymer chain-ends. This extends the possibility of reaction at ambient temperature or polymerization of a broader scope of monomers. To overcome these new challenges, N-heterocyclic carbenes (NHCs) are one of the most promising organocatalysts.

NHCs are neutral divalent carbon species including only six valence electrons. Four are involved in $\sigma$-bonds with generally two adjacent nitrogen atoms, and two non-bonding electrons remain at the central carbon atom. ${ }^{[4]}$ High (Brønsted/Lewis) basicity, strong nucleophilicity and structural versatility are the main attributes of NHCs. The field of NHC-mediated polymerizations has been extensively investigated and has rapidly expanded over the past ten years. The main successful examples include anionic ring-opening chain-growth polymerization (lactones, ${ }^{[5]}$ lactams, ${ }^{[6]}$ epoxides, ${ }^{[7]}$ or cyclosiloxanes ${ }^{[8]}$ ) and to less extent some step-growth polymerization (polyurethane, ${ }^{[9]}$ transesterification, ${ }^{[10]}$ benzoin condensation $\left.{ }^{[11,12]}\right)$.

While NHCs are highly effective in various polymerization reactions paradigms, the downside is their high sensitivity towards air and water, which necessitates handling under rigorously anhydrous conditions using standard glove box or Schlenk techniques. In situ preparation of NHCs has been the alternative strategy to circumvent this problem. The most general methods include the deprotonation or reduction of imidazolium salt, ${ }^{[13]}$ but this method requires the addition of an external reactant and a mixing stage to ensure homogenization. More practical and viable industrially are latent NHCs, where free NHCs are created after application of an external stimulus, such as heat or radiation. An ideal protected NHC is robust and can be stored indefinitely outside an inert atmosphere. Therefore, the catalyst may be weighed out on bench utilizing normal methods, and storable one-component mixtures containing both monomer and catalyst may be prepared to reduce cost, and ease processing in particular for cross-linking reactions. Today, the development of stable, easy-to-prepare-and-handle latent NHC complexes that are readily activated under the reaction conditions is a very important issue to extend the use of NHC in academic and industrial laboratories. To date, thermal dissociation of NHC adducts (NHC- $\mathrm{CO}_{2}$, NHC-alcohol, NHC-hydrogen carbonates, NHC-metal complexes) is the most widely used mode of releasing free NHCs on demand ${ }^{[14]}$ As major achievements, the use of imidazol(in)ium carboxylate $\left(\mathrm{NHC}-\mathrm{CO}_{2}\right)$ has proved an efficient approach for the ring-opening polymerization of cyclic esters and the synthesis of epoxy/anhydride thermoset. ${ }^{[3,15,16]}$ However, it is very challenging to control $\mathrm{CO}_{2}$ adduct activity and dissociation rate, and preserve latency at ambient temperature.

A major step forward, then, would be to develop a NHC photogenerator, i.e. activable upon irradiation, and using readily available starting materials on a large scale. We envisioned that a photolatent NHC would have distinctive advantages compared to a thermally latent analogue: release of free NHC at ambient temperature (considering that many NHC-mediated polymerizations can be conducted without heating), higher temporal resolution in the order of seconds, and spatial resolution opening novel applications such as photolithography. Recently, we described a NHC photogenerating system activable at $365 \mathrm{~nm}$ around a simple concept. It consists of 2-isopropylthioxanthone (ITX) as 
photosensitive species and 1,3-bis(mesityl)imidazolium tetraphenylborate ( $\mathrm{IMesH}^{+} \mathrm{BPh}_{4}^{-}$) acting as NHC protected form. As described in Scheme 1, the photochemical reaction proceeds in two consecutive steps: after radiation absorption, thioxanthone triplet excited state is photoreduced by the borate anion, subsequent proton transfer takes place from imidazolium cation to produce the expected NHC, 1,3-bis(mesityl)imidazol-2-ylidene (IMes). ${ }^{[17]}$ To the best of our knowledge, it was the first photolatent NHC system. In 2013, Bielawski et al. developed a NHC exhibiting only a photoswitchable activity, ${ }^{[18]}$ in the sense that change from visible light to UV caused a cyclization reaction, resulting in a NHC-alcohol devoid of activity.

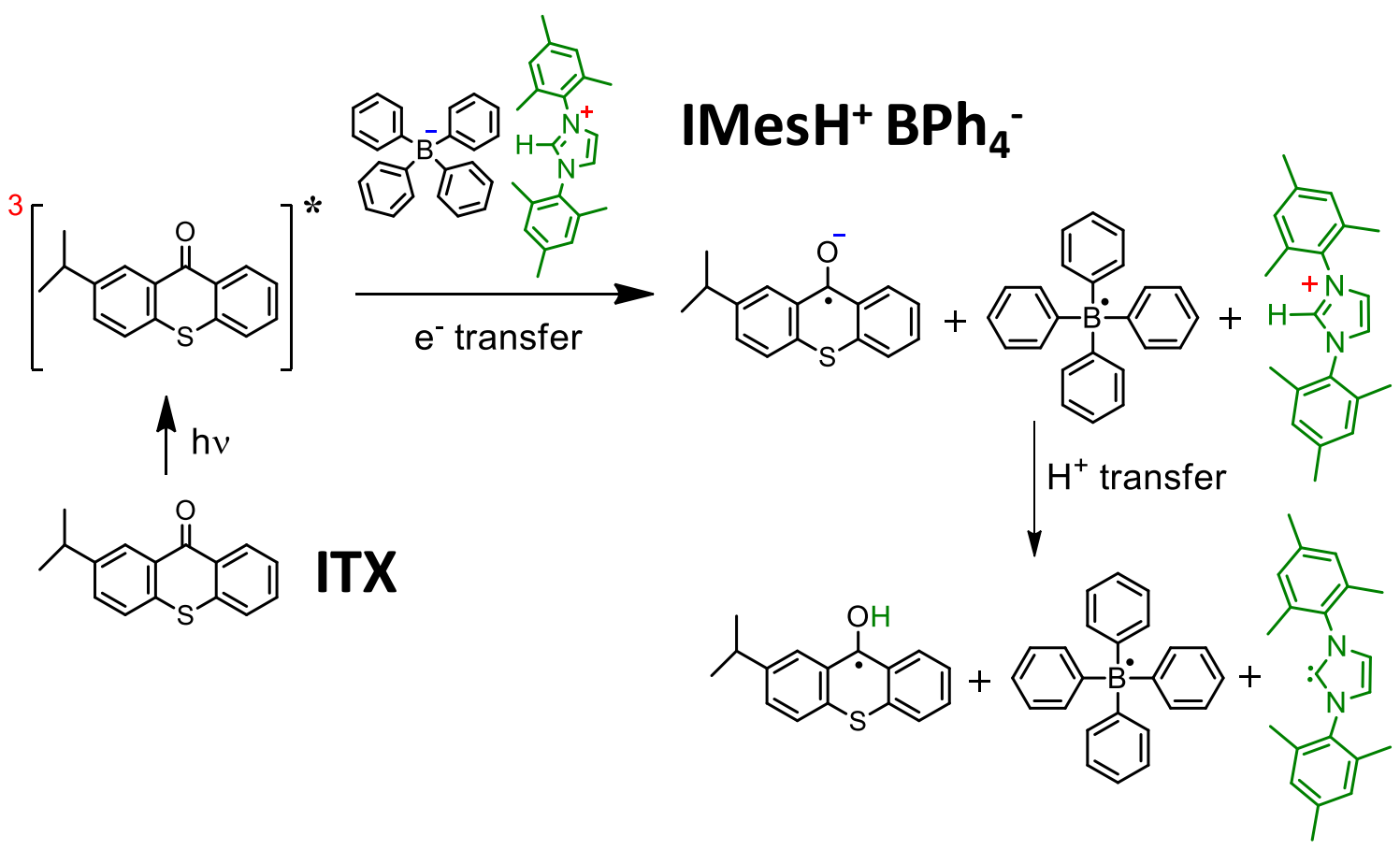

Scheme 1. Photochemical mechanism for NHC (IMes) formation from bicomponent mixture $\mathrm{IMesH}^{+}$ $\mathrm{BPh}_{4}{ }^{-} / \mathrm{ITX}$

In order to demonstrate the utility of this photolatent catalysis, its activity was evaluated in thiol-Michael reactions for small molecule synthesis first, then polymer synthesis via step-growth polymerization. Thiol-Michael addition polymers have found a plethora of applications ranging from polymer modifications of biological systems to hydrogels. ${ }^{[19]}$ As illustrated in Scheme 2, this reaction involves the use of catalytic amount of base/nucleophile to facilitate the reaction between a thiol and an electron deficient vinyl group to yield a thioether. In 2012, Bowman et al. demonstrated that imidazole derivatives showed better catalytic activity than conventional tertiary amine for the thiolMichael reaction. ${ }^{[20]}$ However, the activity of NHC imidazoline and imidazolidine species, which are the most common NHCs, have never been examined. All thiol-X reactions are generally highly dependent of the $\mathrm{pK}_{\mathrm{a}}$ of the thiol along with its structure. Compared to a conventional base, a strong nucleophile such as NHC as catalyst is likely to accommodate a broader range of thiols and Michael substrates while driving high reaction rates. In this report, a systematic approach has been used to study NHC-catalyzed thiol-Michael reactions. The feasibility of photoNHC catalysis in simple coupling reaction with small molecules was firstly assessed, then the synthesis of cross-linked polymer was investigated (see monomer list in Table 1). 


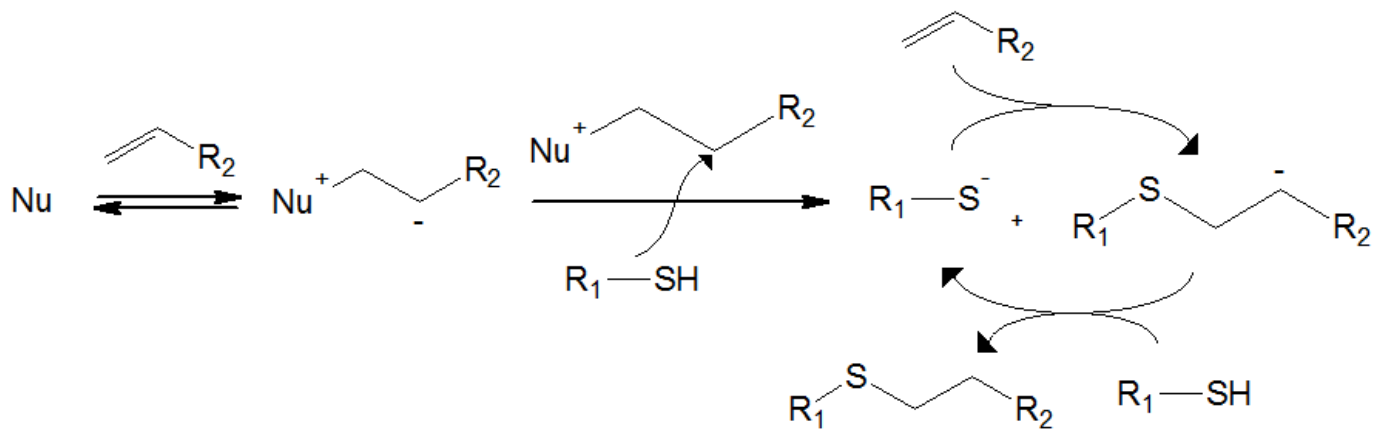

Scheme 2. Nucleophile $(\mathrm{Nu})$-catalyzed mechanism of thiol-Michael addition reaction.

Table 1. Chemical structures of thiol and alkene monomers

THIOL

ACRYLATE

\section{EXPERIMENTAL SECTION}

\section{Chemicals}

1,3-bis(mesityl)imidzolium tetraphenylborate $\left(\mathrm{IMesH}^{+} \mathrm{BPh}_{4}^{-}\right)$was synthesized following an established procedure. ${ }^{[17]}$ 2-isopropylthioxanthone (ITX, $97 \%$ ), methyl acrylate (MA, $99 \%$ ), 1,3bis(mesityl)imidzolium chloride $\left(\mathrm{IMesH}^{+} \mathrm{Cl}^{-}\right.$), sodium tetraphenylborate $\left(\mathrm{NaBPh}_{4}\right)$, butyl acrylate (BuA, 99\%), pentaerythritol tetrakis(3-mercaptopropionate) (PETMP, $95 \%$ ), 2,2,6,6tetramethylpiperidie 1-oxyl free radical (TEMPO, 98\%), N,N-bis-(2,6-dimethylphenyl)carbodiimide (CDI) were purchased from Sigma-Aldrich. 1,6-hexanediol diacrylate stabilized with MEHQ (HDDA, $98 \%$ ), 1-hexanethiol (98\%), butyl thiolglycolate $(98 \%)$ were purchased from TCI Europe. All chemicals reagents were obtained commercially and used without further purification. Tetrahydrofuran (THF), acetonitrile (ACN) were purchased from Carlo Erba. Acetonitrile- $d^{3}$ and THF- $d^{8}$ were purchased from Sigma-Aldrich. All solvents were stored in molecular sieves.

\section{Protocols used for thiol-Michael reactions}

All samples display a stoichiometric amount of thiol and acrylate functions.

1-component system. A borosilicate $\mathrm{NMR}$ tube was charged with $\mathrm{IMesH}^{+} \mathrm{BPh}_{4}^{-}(5.3 \mathrm{mg}, 0.008$ mmol, 2 eq), ITX (1 mg, $0.004 \mathrm{mmol}, 1 \mathrm{eq})$ and TEMPO (1 mg, $0.006 \mathrm{mmol}, 1.5 \mathrm{eq})$. In a control experiment, the mixture $\mathrm{IMesH}^{+} \mathrm{BPh}_{4}-/ \mathrm{ITX}$ was replaced by free IMes ( $\left.2.5 \mathrm{mg}, 0.008 \mathrm{mmol}, 2 \mathrm{eq}\right)$. 
PETMP (122 mg, $0.25 \mathrm{mmol}, 62.5$ equiv.) and HDDA (113 mg, $0.5 \mathrm{mmol}, 125$ equiv.) were added to the NMR tube. Acetonitrile- $d^{3}\left(0.03 \mathrm{M}\right.$, relative to $\left.\mathrm{IMesH}^{+} \mathrm{BPh}_{4}^{-}, 0.3 \mathrm{~mL}\right)$ was added, and the NMR tube was capped with a rubber septum, degassed in $\mathrm{N}_{2}$ atmosphere $(1 \mathrm{~min})$ and irradiated for a variable duration (1-5 $\mathrm{min}$ ) in a LED strip photochemical reactor at room temperature. As sketched in Figure 1, the LED reactor was constructed by winding a LED strip (365 nm, Lightingwill, SMD352, 60 LEDs $/ \mathrm{m}$ ) around a quartz cylinder (internal diameter: $5.5 \mathrm{~cm}$, length: $20 \mathrm{~cm}$ ). 5 coils of LED were assembled, leading to a total length of $86 \mathrm{~cm}$. The NMR tube was introduced in the axis of the quartz cylinder. The distance between the tube surface and the coiled LED array was $2.25 \mathrm{~cm}$. At this distance, the estimated irradiance was $6.5 \mathrm{~mW} \mathrm{~cm}^{-2}$ at $365 \mathrm{~nm}$.

2-component system. a borosilicate $\mathrm{NMR}$ tube 1 was charged with $\mathrm{IMesH}^{+} \mathrm{BPh}_{4}^{-}(5.3 \mathrm{mg}$, $0.008 \mathrm{mmol}, 2 \mathrm{eq})$, ITX (1 mg, $0.004 \mathrm{mmol}, 1 \mathrm{eq})$ and TEMPO (1 mg, $0.006 \mathrm{mmol}, 1.5 \mathrm{eq})$ with acetonitrile- $d^{3}(0.2 \mathrm{~mL})$ and capped with a rubber septum, degassed in $\mathrm{N}_{2}$ atmosphere $(1 \mathrm{~min})$ and irradiated for a duration of 1-5 min in a LED strip photochemical reactor at room temperature. The asirradiated tube was added to a NMR tube 2 containing a mixture of PETMP (122 mg, $0.25 \mathrm{mmol}, 62.5$ eq), HDDA (113 mg, $0.5 \mathrm{mmol}, 125$ equiv) dissolved in acetonitrile- $d^{3}(0.1 \mathrm{~mL})$. Prior to the addition of pthe hotogenerated NHC, the tube 2 was degassed $\left(\mathrm{N}_{2}, 1 \mathrm{~min}\right)$ and capped with a rubber septum.

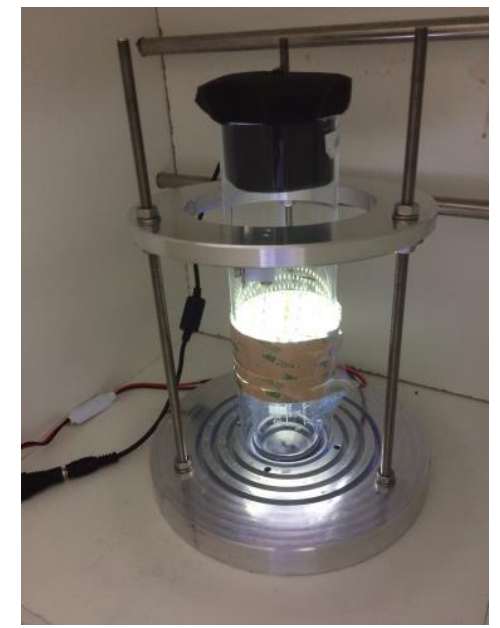

Figure 1. LED photoreactor built by winding a $365 \mathrm{~nm}$ LED strip around a quartz cylinder. NMR tube is placed at the center.

\section{CHARACTERIZATION}

Fourier Transform Infrared Spectroscopy (FTIR) analysis was performed using a Nicolet iS50 equipped with a horizontal accessory. The FTIR spectra were treated using OMNIC 9.8 software. The spectra were recorded by a deuterated triglycine sulfate (DTGS) detector with a $\mathrm{KBr}$ beam splitter. All kinetics were monitored at a scan rate of one scan per $1.5 \mathrm{~s}$. In a solution thiol-Michael photopolymerization experiment, a two-component formulation (see previous section) was introduced in a $5 \mathrm{~mL}$ Sulzer Mixpac ${ }^{\mathrm{TM}}$ mixer containing two separate cartridges: one for the monomers (HDDA/PETMP) and the second for as-irradiated $\mathrm{IMesH}^{+} \mathrm{BPh}_{4}-$ /ITX/TEMPO (5 min). This double syringe enabled to mix both components together and introduce the reactive medium in a demountable IR liquid sandwich cell consisting of two $\mathrm{CaF}_{2}$ windows separated by a lead Teflon spacer $(1 \mathrm{~mm})$. The spacer and windows form a sealed liquid sample compartment with a steady path length. Our configuration uses $38.5 \times 19.5 \times 4 \mathrm{~mm}$ rectangular windows, the inlet of the front plate allows introduction of the reactive mixture without disassembling the cell, before the onset of gelation. FTIR analysis was triggered just after the IR cell filling. The conversion of thiol and acrylate functional 
groups were assessed approx. $10 \mathrm{~s}$ after mixture preparation by monitoring the gradual disappearance of the IR bands centered at $2580 \mathrm{~cm}^{-1}$ ( $v_{\mathrm{SH}}$ stretching mode) and $1620 \mathrm{~cm}^{-1}$ ( $v_{\mathrm{C}=\mathrm{C}}$ stretching mode) respectively. In a variant process referred to as bulk polymerization, the reaction mixture coming out from the double syringe was cast on a $25 \mathrm{~mm}$ diameter circular $\mathrm{KBr}$ window.

Carbodiimide-NHC adduct formation. A borosilicate NMR tube was charged with $\mathrm{IMesH}^{+}$ $\mathrm{BPh}_{4}^{-}(10 \mathrm{mg}, 0.015 \mathrm{mmol}, 2 \mathrm{eq})$ and ITX $(2 \mathrm{mg}, 0.008 \mathrm{~mol}, 1 \mathrm{eq})$. THF- $d^{8}$ (0.03 M, relative to $\mathrm{IMesH}^{+} \mathrm{BPh}_{4}^{-}, 0.5 \mathrm{~mL}$ ) was added and the NMR tube was capped with a rubber septum and irradiated for a variable duration ( $30 \mathrm{sec}-10 \mathrm{~min}$ ) with a LED waveguide (Hamamatsu spot light source LCL1V3). $12 \mathrm{mg}$ (2 eq) of N,N-bis-(2,6-dimethylphenyl)carbodiimide (CDI) was then added into the NMR tube to have a 1:1 stoichiometric ratio with $\mathrm{IMesH}^{+} \mathrm{BPh}_{4}^{-}$. The reaction media immediately changed color from yellow solution to orange. The formation of the soluble zwitterionic adduct IMesCDI was confirmed by ${ }^{1} \mathrm{H}-\mathrm{NMR}$ spectroscopy and its yield determined.

Gel content measurement of the polymer formed after thiol-Michael polymerization was performed after different irradiation times (30 s $-5 \mathrm{~min}$ ). After $10 \mathrm{~min}$ storage, the polymers were dried at $70^{\circ} \mathrm{C}$ under vacuum at least $8 \mathrm{~h}$ to remove all volatile compounds (solvent, monomer), weighed and soaked in THF solvent overnight. The solid products were filtrated, dried and weighed again to observe any change of mass.

$$
\text { Gel content }=\frac{W_{1} * 100}{W_{2}}
$$

$W_{1}$ is the weight of the insoluble fraction after washing, and $W_{2}$ is the weight of the original polymer after photopolymerization and drying.

Nuclear Magnetic Resonance (NMR). NMR spectra were recorded on a Varian Mercury Plus $300 \mathrm{MHz}$ NMR spectrometer operating at $25{ }^{\circ} \mathrm{C}$ in acetonitrile-d $\mathrm{d}^{3}$. VNMRJ software was used for proton analysis. All chemical shifts were reported in ppm relative to acetonitrile solvent.

Optical pyrometry. The use of pyrometry to follow photopolymerization reactions was developed by Crivello et al. ${ }^{[21]}$ In this study, we used a thermometer Ebro TFN-530 probe to follow the change of temperature in a 2-component system. The probe was dipped in the solution of monomers. Temperature measurement started after addition of photogenerate IMes to PETMP/HDDA mixture. Change of temperature value every $5 \mathrm{~s}$ was reported until a steady temperature close ambient temperature was reached.

\section{RESULTS AND DISCUSSIONS}

\section{Photogeneration of NHC}

Organoborates have been well established as one-electron reducing agents (electron donors) in a variety of thermal and photochemical redox processes. ${ }^{[22]}$ In a recent example, we used tetraphenylborate imidazolium salt $\left(\mathrm{IMesH}^{+} \mathrm{BPh}_{4}^{-}\right)$in combination with the thioxanthone derivative ITX as NHC photogenerating system ${ }^{[17]}$ in which the key steps involve an initial photoinduced electron transfer and subsequent proton transfer (Scheme 1). Another well-known example proceeding through the same mechanism is ITX/tertiary amine serving as free radical initiators in photopolymerization of acrylates. ${ }^{[23]}$ Electron transfer is induced by photo-excitation of ITX because its shift to triplet excited state $\left({ }^{3}\right.$ ITX $\left.^{*}\right)$ drives an increase of oxidant properties. Therefore, NHC generation can be controlled by radiation at $365 \mathrm{~nm}$ where only ITX absorbs while the imidazolium salt behaves as stable and protected NHC form. In our system, use of 1,3-bis(mesityl)imidazolium 
tetraphenylborate $\left(\mathrm{IMesH}^{+} \mathrm{BPh}_{4}^{-}\right)$enables the formation of the well-known NHC: 1,3dimesitylimidazol-2-ylidene also referred to as IMes. To determine the yield of NHC photogenerated, IMes was converted into a stable adduct by addition of carbodiimide into the as-irradiated $\mathrm{IMesH}^{+}$ $\mathrm{BPh}_{4}{ }^{-} / \mathrm{ITX}$ (see experimental procedure). Moisture-stable "NHC-CDI" adducts or zwitterionic-type amidinates can be well identified by ${ }^{1} \mathrm{H}-\mathrm{NMR}$ spectroscopy (not given), the quantity of adduct being the mirror of the quantity of IMes photogenerated. The IMes-CDI adduct was achieved by the direct treatment of the corresponding CDI with a IMes in a 1:1 stoichiometric ratio in THF at room temperature. ${ }^{[24]}$ Control experiments with free IMes validated this process as relatively precise titration method $( \pm 2 \%)$. A maximum yield of $32 \%$ was reached after $10 \mathrm{~min}$ irradiation $\left(65 \mathrm{~mW} \mathrm{~cm}^{-2}\right)$. Longer irradiation led to decomposition of NHC formed, presumably through electron transfer from IMes (a strong nucleophile) to ${ }^{3} \mathrm{ITX}^{*}$.

\section{Thiol-Michael reaction}

\section{II.1 Coupling reaction with small molecules}

To demonstrate the concept of photoNHC-catalyzed thiol-Michael reaction, PETMP and BuA (see Table 1 for structures) were used respectively as thiol and ene reactant in a model non-crosslinking system. The mixture was found to be stable in acetonitrile for at least $24 \mathrm{~h}$ even under radiation exposure. As preliminary experiment, addition of free IMes $(0.5 \mathrm{~mol} \%$ with respect to monomers) resulted in $100 \%$ of conversion (SH and acrylate) after only $2 \mathrm{~min}$, illustrating the efficiency of NHC organocatalyst for thiol-Michael reaction at ambient temperature. Then, reaction of PETMP/BuA (62.5/250 equiv.) was attempted in an NMR tube containing acetonitrile- $d^{3}$ using a mixture of $\mathrm{IMesH}^{+}$ $\mathrm{BPh}_{4}{ }^{-} / \mathrm{ITX} / \mathrm{TEMPO}$ (2/1/1.5 equiv.). TEMPO was incorporated into the photogenerating system to inhibit the radicals produced by the photolysis mechanism. Scheme 1 shows indeed that both NHC and radicals are produced simultaneously, in addition excited ITX is able to abstract $\mathrm{H}$ from thiol to from thiyl radicals. In our case, TEMPO aims to prevent thiol-ene reaction and chain-growth homopolymerization of acrylates. In the monocomponent system, no reaction proceeded without irradiation, supporting photolatency of the photogenerating system. After $5 \mathrm{~min}$ of irradiation $(6.5 \mathrm{~mW}$ $\mathrm{cm}^{-2}$ ), about half thiol and ene reactive functions have been consumed (Figure 2). Control experiments in absence of TEMPO or with higher TEMPO content (3 equiv.) were carried without significant change in reaction kinetics, which agrees with a minimal role played by the radicals in the polymerization progress. The quantity of TEMPO in solution was thus fixed at 1.5 equiv. in the rest of the study.

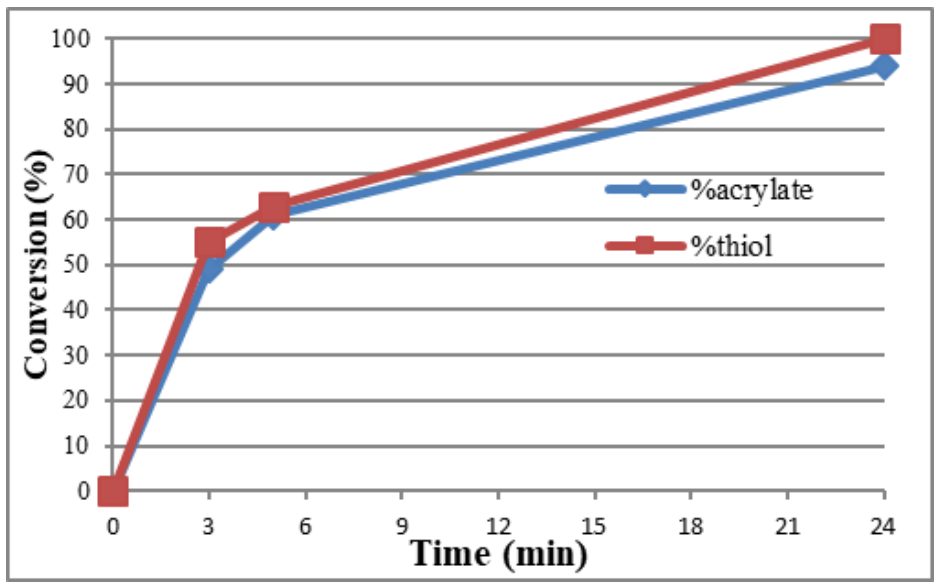

Figure 2. Conversion time plot for thiol-Michael reaction in acetonitrile- $d^{3}$ of PETMP/BuA (62.5/250 equiv.) using $\mathrm{IMesH}^{+} \mathrm{BPh}_{4}{ }_{4} / \mathrm{ITX} / \mathrm{TEMPO}$ (2/1/1.5 equiv). A one-pot procedure was used. 
Nevertheless, the major challenge is ascertaining whether thiol-Michael occurs, and if it does, its extent relative to thiol-ene radical process that results in the same final product. While the synchronous conversion of thiols and acrylates rules out the possibility of homopolymerization, radical mediated thiol-ene is not completely without ambiguity since TEMPO may not scavenge all radicals. The strongest evidence to support a NHC-catalyzed thiol-Michael addition was to proceed with a 2-step procedure: $\mathrm{IMesH}^{+} \mathrm{BPh}_{4}{ }^{-} / \mathrm{ITX} / \mathrm{TEMPO}$ was first irradiated, then transferred to PETMP/BuA reactive mixture to be sure that short-lived radicals do not interfere.

Figure 3 is a functional group conversion plot as a function of time after different irradiation times (1, 2 and $3 \mathrm{~min}$ ) of the $\mathrm{IMesH}^{+} \mathrm{BPh}_{4} / \mathrm{ITX} / \mathrm{TEMPO}$ mixture. Much faster conversion rates were observed. 1 and 2 min irradiation were not sufficient to reach full conversion during irradiation, and there was a gradual increase of thiol and acrylate conversion. Because of the initial nucleophile presence after irradiation, it is actually expected that the thiol-Michael reaction continues in the dark even after cessation of irradiation. Such living character is instrumental in radiation curing to allow conversions of unexposed areas and reach higher conversions. The fact that both reactive functions are consumed approx. at the same rate is consistent with a thiol-Michael reaction. The slight imbalance between thiol and acrylate conversion was assigned to $\mathrm{SH} / \mathrm{C}=\mathrm{C}$ stoichiometry deviation. With $1 \mathrm{~min}$ irradiation, $90 \%$ conversion was achieved, while full conversions were obtained for longer irradiation times. Low NHC yield after 1 min irradiation can account for the lower NHC yield. Our results illustrate that an increasing amount of NHC species may be generated with longer irradiation time. Because a 2-step process is easier to understand since the identities of the catalytic species are much better established, the rest of the reactions were performed with this methodology.
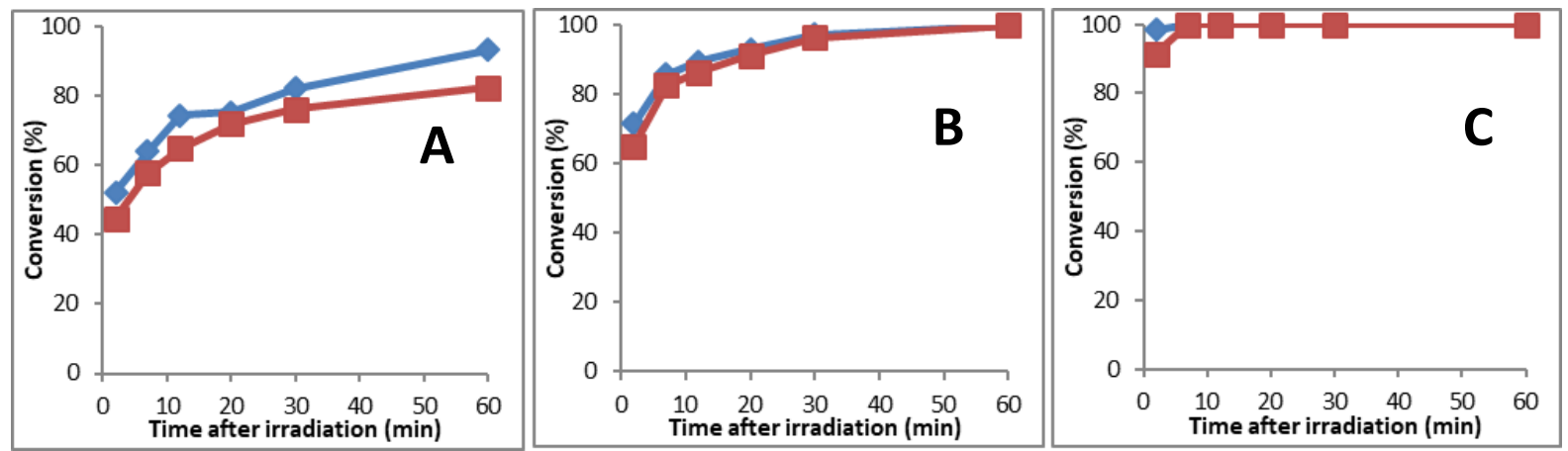

Figure 3. Conversion time plot of thiol and acrylate functions of PETMP/BuA (62.5/250 equiv.) after addition of an irradiated mixture based on $\mathrm{IMesH}^{+} \mathrm{BPh}_{4}{ }^{-} / \mathrm{ITX} / \mathrm{TEMPO}$ (2/1/1.5 equiv.) following a two-step procedure. Different irradiation times were used: A: $1 \mathrm{~min}, \mathbf{B}: 2 \mathrm{~min}$ and $\mathbf{C}: 5 \mathrm{~min} .-$ Acrylate conversion $=$ Thiol conversion. The conversions were determined by ${ }^{1} \mathrm{H}-\mathrm{NMR}$ spectroscopy.

Using PETMP/BuA as model mixture, the effect of the thiol and acrylate structure on thiolMichael reactivity was examined. In a typical experiment, $\mathrm{IMesH}^{+} \mathrm{BPh}_{4}-/ \mathrm{ITX} / \mathrm{TEMPO}$ was irradiated 2 min then introduced into the thiol/acrylate mixture, and conversions determined by ${ }^{1} \mathrm{H}-\mathrm{NMR}$ after 10 min storage. As shown in Table 2, the reaction is negligibly influenced by the structure and functionality of the acrylate. By contrast, thiol structure results in a much stronger effect. An increasing reactivity order was found for alkanethiol (hexanethiol, runs 4-6) > thiolpropionate (PETMP, runs 1-3) > thiolacetate (butyl thioglycolate, runs 7-9). In this latter case, yield was only $31.6 \%$ and $13.1 \%$, with MA and HDDA respectively. These results differ from last works of Chan et al. ${ }^{[25]}$ who demonstrated a reverse in thiol reactivity order using amines and amidines as catalysts. 
Because NHC-catalyzed thiol-Michael reactions proceed via a nucleophile-catalyzed pathway, it is likely that a change in reactivity may happen.

Table 2. Conversion after $10 \mathrm{~min}$ of reaction with photoNHCs followed by ${ }^{1} \mathrm{H}-\mathrm{NMR}$ specroscopy. Thiol/Ene functions 250/250 equiv. was used. $\mathrm{IMesH}^{+} \mathrm{BPh}_{4}-/ \mathrm{ITX} / \mathrm{TEMPO} 2 / 1 / 1.5$ equiv. in acetonitrile- $d^{3}\left(\left[\mathrm{IMesH}^{+} \mathrm{BPh}_{4}^{-}\right]=0.03 \mathrm{M}, \mathrm{V}=0.3 \mathrm{~mL}\right)$.

\begin{tabular}{llll}
\hline Run & Thiol & Acrylate & Yield (\%) \\
\hline 1 & PETMP & BuA & 87 \\
2 & PETMP & MA & 85 \\
3 & PETMP & MMA & 75 \\
4 & Hexanethiol & HDDA & 100 \\
5 & Hexanethiol & MA & 100 \\
6 & Hexanethiol & BuA & 100 \\
7 & Butyl thioglycolate & HDDA & 13 \\
8 & Butyl thioglycolate & MA & 32 \\
9 & Butyl thioglycolate & MMA & 1 \\
\hline
\end{tabular}

\section{II.2 Cross-linking reactions}

Our model cross-linking system contains PETMP and HDDA and a 2-component methodology has been implemented in THF via the addition of photogenerated NHC. Control experiment proved that the monomer mixture was stable. Additionally, the reaction did not occur in the presence of acetic acid suggesting that $\mathrm{NHC}$ acts as organocatalyst. In contrast, immediate gelation takes place after addition of the as-irradiated $\mathrm{IMesH}^{+} \mathrm{BPh}_{4} / \mathrm{ITX} / \mathrm{TEMPO}$ mixture $\left(5 \mathrm{~min}, 6.5 \mathrm{~mW} \mathrm{~cm} \mathrm{~cm}^{-2}\right.$ ) to PETMP/HDDA. Interestingly, the reaction rate was not affected by the change of TEMPO amount in the system, which supports again the prominence of a nucleophile-mediated thiol-Michael reaction. The obtained polymer turned out to be insoluble in various organic solvents, suggesting that a crosslinking reaction occurred.

Obviously, the high reactivity of this system makes the monitoring of the cross-linking kinetics challenging. To overcome this issue, a double syringe was used where the two compartments were filled by the monomer mixture and the catalytic system. By this way, it has been possible to fill a IR liquid cell and follow the reaction kinetics of a solution polymerization by rapid-scan FTIR spectroscopy (see experimental section for details). As can be seen in Figure 4, both thiol and acrylate are consumed at the same rate, which is consistent with a thiol-Michael addition reaction mechanism. The IR spectra show the consumption of $v_{\mathrm{SH}}$ stretching mode $\left(2550 \mathrm{~cm}^{-1}\right)$ and $v_{\mathrm{C}=\mathrm{C}}$ stretching mode $\left(1620 \mathrm{~cm}^{-1}\right)$ exploited to create the kinetic curves for two intermediate times $\mathrm{t}=0$ and $\mathrm{t}=5 \mathrm{~min}$ (still partial conversion). At $5 \mathrm{~min}$, the conversion was at $85 \%$. A complete conversion can be reached in approx. $10 \mathrm{~min}$. 


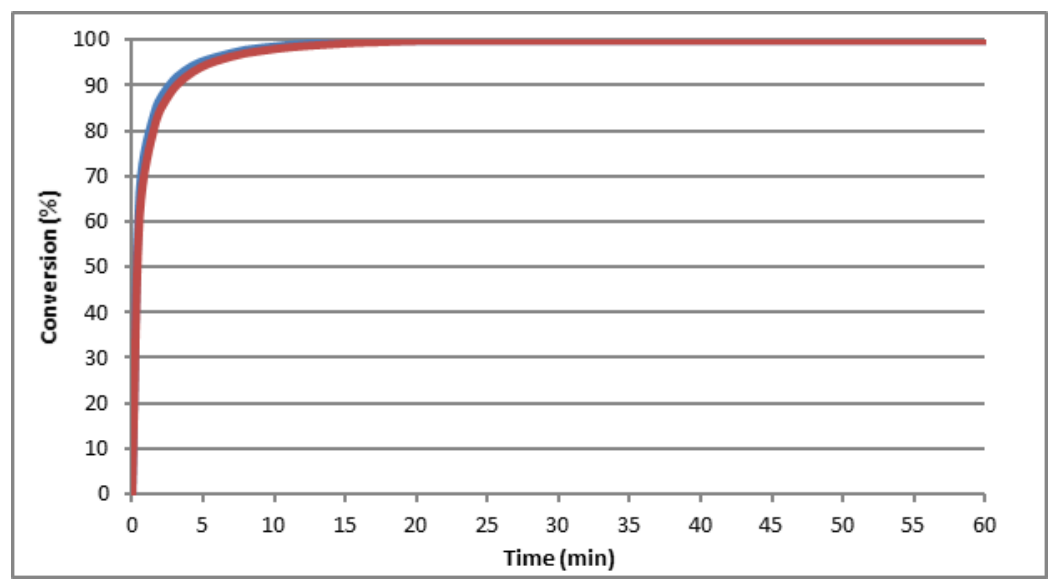

Figure 4. Monomer conversion plot as a function of time for thiol and acrylate functions in IR liquid cell (spacer thickness $=1 \mathrm{~mm}$ ) for solution photopolymerization of PETMP/HDDA: 62.5/125 equiv. (component 1), $\mathrm{IMesH}^{+} \mathrm{BPh}_{4}-$ /ITX/TEMPO: 2/1/1.5 equiv. (component 2) in THF $\left(\left[\mathrm{IMesH}^{+} \mathrm{BPh}_{4}{ }^{-}\right]=\right.$ $0.013 \mathrm{M}, \mathrm{V}=0.6 \mathrm{~mL}$ ). Irradiation time: $5 \mathrm{~min} . \longrightarrow$ thiol conversion, $=$ acrylate conversion.

To monitor reaction progress, gel contents were measured for different irradiation times of $\mathrm{IMesH}^{+} \mathrm{BPh}_{4} / \mathrm{ITX} / \mathrm{TEMPO}$ mixture (30 $\mathrm{s}-5 \mathrm{~min}$, Figure 5). While a limited gel content of $70 \%$ was found for 30 seconds irradiation, longer exposure to UV radiation led to a completely insoluble crosslinked structure.

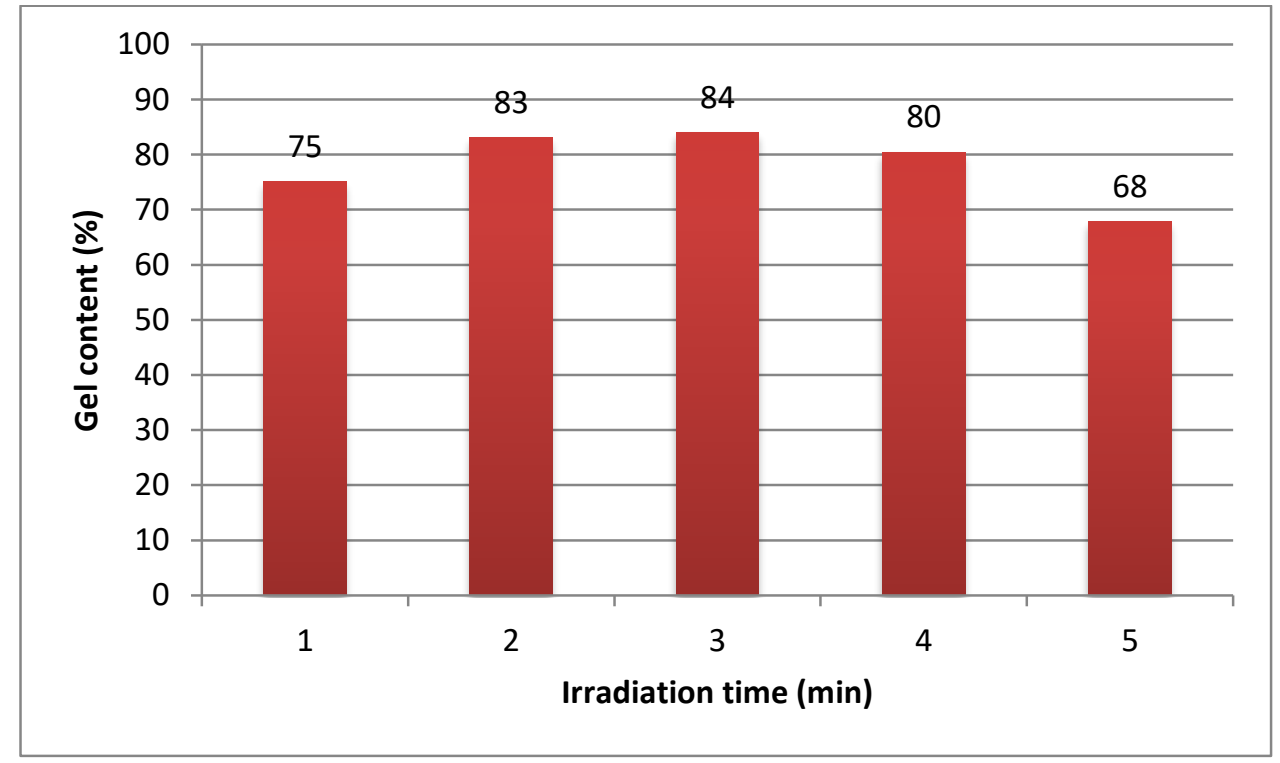

Figure 5. Increase of gel content as a function of irradiation time.

Because of the high exothermicity of thiol-Michael cross-linking reaction, we attempted to use pyrometry to evaluate the change of temperature during the photoinduced polymerization of HDDA/PETMP catalyzed by $\mathrm{IMesH}^{+} \mathrm{BPh}_{4}{ }^{-} / \mathrm{ITX}$. $20 \mathrm{~s}$ after addition of photogenerated IMes $(5 \mathrm{~min}$ irradiation), temperature reaches a maximum at $38^{\circ} \mathrm{C}$ (Figure 6). The reaction is reproducible and higher maximum temperature can be obtained upon adding a higher concentration of photoNHC catalysts. For this reason, coupling of real-time infrared spectroscopy with optical IR pyrometry is a useful method for simultaneously monitoring the chemical conversion and the temperature. 


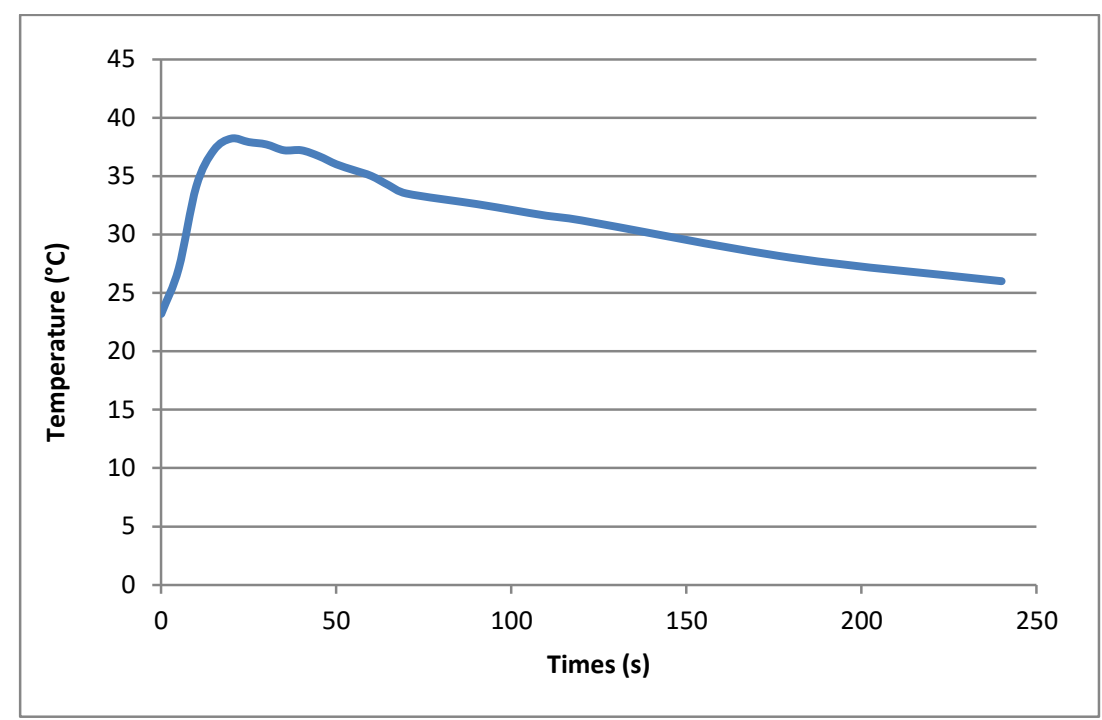

Figure 6. Temporal change of temperature in the course of photoNHC-catalyzed polymerization of PETMP/HDDA.

\section{CONCLUSION}

The utility of a photolatent NHC organocatalyst for the photochemical activation of thiol-Michael reaction has been demonstrated. Using a two-step procedure to prevent adventitious radical-mediated thiol-ene reaction, the NHC molecule IMes was first photogenerated in solution with a mixture of $\mathrm{IMesH}^{+} \mathrm{BPh}_{4}^{-} / \mathrm{ITX}$ (2/1 equiv.), then introduced into a stoichiometric thiol/ene reactant mixture (250 equiv. of ene and thiol function). 5 min irradiation of the NHC photogenerating system enabled a complete reaction of the PETMP/BuA mixture in the matter of minutes. This results supports the efficient photogeneration of Imes, that was previously established in control experiments. In addition to coupling reactions between small molecules, the synthesis of cross-linked polymers was also reported via a step-growth polymerization mechanism. Using the same photocatalyst system, we proved that the tetrathiol/diacrylate mixture PETMP/HDDA achieved full conversion in less than 1 min through FTIR spectroscopy. Nevertheless, further efforts are required to study thiol-Michael reactivity with a broader range of ene and thiol monomers. We foresee that the photolatent IMes can be a potential candidate for the organocatalysis of transesterification reactions or other thiol-X reactions such as thiol-isocyanate with many advantages including easier handling of chemicals better temporal and spatial control of the reaction.

\section{REFERENCES}

1. Dove, A. P. ACS Macro Lett., 2012, 1 (12), 1409-1412.

2. Kiesewetter, M. K.; Shin, E. J.; Hedrick, J. L.; Waymouth, R. M. Macromolecules, 2010, 43 (5), $2093-2107$.

3. Ottou, W. N.; Sadro, H.; Mecerreyes, D.; Vignolle, J.; Taton, D. Prog. Polym. Sci., 2016, 56, $64-115$.

4. Bourrissou, D.; Guerret, O.; Gabbai, F. B.; Bertrand, G. Chem. Rev., 2000, 100 (1), 39-92.

5. Matyjaszewski, K.; Möller, M. Polymer science: A comprehensive reference, Elsevier, 2012 (4), 67-115.

6. Naumann, S.; Epple, S.; Bonten, C.; Buchmeiser, M. R. ACS Macro Lett., 2013, 2 (7), 609-612.

7. Raynaud, J.; Absalon, C.; Gnanou, Y.; Taton, D. J. Am. Chem. Soc., 2009, 131 (9), 3201-3209.

8. Grzelka, A.; Chojnowski, J.; Fortuniak, W.; Taylor, R. G.; Hupfield, P. C. J. Inorg. Organomet. Polym., 2004, 14 (2), 85-99.

9. Bantu, B.; Pawar, G. M.; Decker, U.; Wurst, K.; Schmidt, A. M.; Buchmeiser, M. R. Chem. Eur. J., 2009, 15 (13), 3103-3109. 
10. Enders, D.; Niemeier, O.; Henseler, A. Chem. Rev., 2007, 107 (12), 5606-5655.

11. Enders, D.; Kalfass, U. Angew. Chem. Int. Ed., 2002, 41, 1743-1745.

12. Knight. R.L.; Lepeper, F. J. J. Chem. Soc., Perkin Trans. 1, 1998, 1891-1894.

13. Fèvre, M.; Pinaud, J.; Ganou, Y.; Vignolle, J.; Taton, D. Chem. Soc. Rev., 2013, 42, 2142-2172.

14. Nyce, G. W.; Csihony, S.; Waymouth. R. M. Chem. Eur. J., 2004, 10 (16), 4073-4079.

15. Naumann, S.; Schmidt, F. G.; Speiser, M.; Böhl, M.; Epple, S.; Bonten, C.; Buchmeiser, M. R. Macromolecules, 2014, 47 (14), 4548-4556.

16. Pinaud, J.; Vignolle, J.; Gnanou, Y.; Taton, D. Macromolecules, 2011, 44 (7), 1900-1908.

17. Pinaud, J.; Trinh, T. K. H.; Sauvanier, D.; Placet, E.; Songsee, S.; Lacroix-Desmazes, P.; Becht, J-M.; Tarablsi, B.; Lalevée, J.; Picavant, L; Héroguez, V.; Chemtob, A. Chem. Eur. J., 2018, 24, 337-341.

18. Neilson, B. M.; Bielawski, C. W. Chem. Commun., 2013, 49, 5453-5455.

19. Nair, D. P.; Podgórski, M.; Chatani, S.; Gong, T.; Weixian, X.; Fenoli, C. R.; Bowman. C. N. Chem. Mat., 2014, 26, 724-744.

20. Xi, W.; Wang, C.; Kloxin, C. J.; Bowman. C. N. ACS Macro Lett., 2012, 1 (7), 811-814.

21. Falk, B.; Vallinas, S. M.; Crivello, J. V. J. Polym. Sci., Part A: Polym. Chem., 2003, 41 (4), 579-596.

22. Zhu, D.; Kochi, J. K. Organometallics, 1999, 18 (2), 161-172.

23. Nayak, B. R.; Mathias, L. J. J. Polym. Sci., Part A: Polym. Chem., 2005, 43 (22), 5661-5670.

24. Baishya, A.; Kumar, L.; Barman, M. K.; Peddarao, T.; Nembenna, S. Chemistry Select, 2016, 1 (3), 498-503.

25. Chan. J. W.; Hoyle, C. E.; Lowe, A. B.; Bowman, C. N. Macromolecules, 2010, 43 (15), 6381-6388. 